\title{
Use of Antiasthmatic Drugs during Pregnancy after the First Trimester and Maternal and Neonatal Outcomes
}

\author{
Bengt Källén $^{1}$ and Birgitta Norstedt Wikner ${ }^{2,3}$ \\ ${ }^{1}$ Tornblad Institute, Lund University, Biskopsgatan 7, 22362 Lund, Sweden \\ ${ }^{2}$ National Board of Health and Welfare, 10630 Stockholm, Sweden \\ ${ }^{3}$ Department of Medicine, Centre for Pharmacoepidemiology, Karolinska Institutet, 17176 Stockholm, Sweden \\ Correspondence should be addressed to Bengt Källén; bengt.kallen@med.lu.se
}

Received 2 September 2014; Accepted 24 October 2014; Published 13 November 2014

Academic Editor: Christian Kähler

Copyright (c) 2014 B. Källén and B. Norstedt Wikner. This is an open access article distributed under the Creative Commons Attribution License, which permits unrestricted use, distribution, and reproduction in any medium, provided the original work is properly cited.

\begin{abstract}
Background. Women with asthma using antiasthmatics during the later part of the pregnancy have an increased risk for obstetric complications and their infants of neonatal complications. Material and Methods. The study is based on a linkage between the Swedish Medical Birth Register and a register of prescribed drugs in Sweden for the years 2009-2011, identifying women who had filled prescriptions for antiasthmatics after the first trimester. Their characteristics, their obstetric history, and the neonatal conditions of their infants were compared with all other women who gave birth. Adjusted Mantel-Haenszel odds ratios were determined. Results. We found an increased risk for a number of maternal conditions but no risk increase for gestational diabetes (after adjustment for body mass index) or for premature rupture of membranes. There was an increase in preterm births for some drugs used at severe asthma and of low birth weight and small for gestational age for most drug combinations. An increased risk was seen for neonatal hypoglycemia, respiratory problems, and low Apgar score. Conclusions. There are many hazards associated with maternal asthma and use of antiasthmatic drugs. Most evidence suggests a disease effect. A careful control of the asthma during pregnancy is important.
\end{abstract}

\section{Introduction}

Many articles and reviews are available on the subject of asthma and the use of antiasthmatic drugs during pregnancy. One review [1] summarized the early literature. More recent reviews have been published [2-4]. In most studies which were large enough, an association with various maternal obstetric morbidities was demonstrated. On the other hand, the effect on preterm birth, low birth weight, and intrauterine growth retardation is more uncertain and results vary.

A recent paper [5] studied the issue of congenital malformation risk after early pregnancy exposure to antiasthmatic drugs and a weak general increase was found which could not be attributed to any specific antiasthmatic drug and most likely was due to the effect of the underlying disease. In the present study, the effect of use of antiasthmatics later in pregnancy is studied.

\section{Material and Methods}

The study was based on the Swedish Medical Birth Register [6] which contains medical information on practically all deliveries in Sweden since 1973, including information on delivery and neonatal diagnoses. Information on the use of antiasthmatic drugs was obtained from the Swedish Prescribed Drugs Register [7]. Women giving birth during 2009-2011 were searched in this register and the filling of prescriptions of antiasthmatic drugs within a year before delivery was identified. The gestational week of filling the prescription was calculated from the date of filling the prescription and the estimated date of the last menstrual period (LMP). LMP was determined from the date of delivery and the pregnancy duration in days, mainly evaluated by second trimester sonography. Drugs were classified by the Anatomical Therapeutic Chemical (ATC) Classification System. The code for an antiasthmatic drug was R03. 
TABLE 1: Overview of antiasthmatic drugs prescribed to women within one year before delivery.

\begin{tabular}{|c|c|c|c|}
\hline Drug group & Drug name & ATC-code & Number of women \\
\hline \multirow{2}{*}{ Inhaled short-acting $\beta$-agonist } & Salbutamol & R03AC02 & 2099 \\
\hline & Terbutaline & $\mathrm{R} 03 \mathrm{AC} 03$ & 5284 \\
\hline \multirow{3}{*}{ Inhaled long-acting $\beta$-agonist } & Salmeterol & $\mathrm{R} 03 \mathrm{AC} 12$ & 102 \\
\hline & Formoterol & $\mathrm{R} 03 \mathrm{AC} 13$ & 503 \\
\hline & Indacaterol & $\mathrm{R} 03 \mathrm{AC} 18$ & 1 \\
\hline $\begin{array}{l}\text { Inhaled combined short-acting } \beta \text {-agonist with } \\
\text { other drug }\end{array}$ & Salbutamol + ipratropium & R03AK04 & 39 \\
\hline \multirow{2}{*}{$\begin{array}{l}\text { Inhaled combined long-acting } \beta \text {-agonist with } \\
\text { corticosteroid }\end{array}$} & Salmeterol + fluticasone & R03AK06 & 535 \\
\hline & Formoterol + budesonide & R03AK07 & 1594 \\
\hline \multirow{4}{*}{ Inhaled corticosteroid } & Beclometazone & R03BA01 & 75 \\
\hline & Budesonide & R03BA02 & 4175 \\
\hline & Fluticasone & R03BA05 & 220 \\
\hline & Mometasone & R03BA07 & 23 \\
\hline \multirow{2}{*}{ Anticholinergics } & Ipratropium & R03BB01 & 31 \\
\hline & Thiotropium & R03BB04 & 7 \\
\hline Antiallergics & Cromoglicic acid & $\mathrm{R} 03 \mathrm{BC} 01$ & 19 \\
\hline \multirow{3}{*}{ Oral adrenergics } & Ephedrine & R03CA02 & 1 \\
\hline & Salbutamol & R03CC02 & 38 \\
\hline & Terbutaline & $\mathrm{R} 03 \mathrm{CC} 03$ & 2474 \\
\hline \multirow{2}{*}{ Xanthines } & Choline theophyllinate & R03DA02 & 10 \\
\hline & Theophylline & R03DA04 & 12 \\
\hline Leuotriene receptor antagonist & Montelukast & R03DC03 & 231 \\
\hline Antibody & Omalizumab & R03DX05 & 1 \\
\hline
\end{tabular}

The following outcomes were studied, defined by International Statistical Classification of Disease and Related Health Problems, 10th edition (ICD-10) codes, or from other register data.

Maternal delivery diagnoses are preexisting diabetes, preexisting hypertension, gestational diabetes, preeclampsia, hyperemesis gravidarum, placenta previa, abruption of placenta, premature rupture of membranes (PROM), hemorrhage around delivery, induction of delivery, caesarean section, and instrumental vaginal delivery.

Neonatal characteristics studied were preterm birth in singletons ( $<37$ weeks), low birth weight in singletons $(<2500 \mathrm{~g})$, and small for gestational age (SGA) in singletons ( $<2$ standard deviations below the expected weight for gestational duration, infant sex, and parity) [8].

The investigated neonatal diagnoses were hypoglycemia, fetal distress, respiratory diagnoses, Apgar score $<7$ at 5 minutes, intracranial hemorrhage, diagnoses referring to central nervous system (CNS) symptoms, and jaundice.

Risk estimates were made with Mantel-Haenszel procedure as odds ratios (OR) with approximate 95\% confidence intervals (95\% CI) estimated with Miettinen's method. Adjustment was made for year of birth, maternal age, parity, smoking in early pregnancy, and prepregnancy body mass index (BMI). When the expected number of outcomes was $<10$, risk ratios $(\mathrm{RR})$ were instead determined as the observed overexpected number, the latter estimated after adjustments as above. Exact 95\% CI were based on Poisson distributions.

\section{Results}

During the period 2009-2011, 17391 women with 17740 infants were identified as having filled a prescription for an antiasthmatic drug within a year before the delivery. Table 1 shows the distribution between specific drugs.

Orally taken terbutaline was, however, mainly used for premature uterine contractions towards the end of the pregnancy and such exposures were therefore excluded when no other antiasthmatic drug was used. Then 10553 women with 10728 infants remained with prescriptions filled during trimesters 2-3. In the register, a total of 327932 women with 332682 infants were registered these years. Thus $3.2 \%$ of the women had filled at least one prescription for an antiasthmatic drug.

Figure 1 shows that the prescription rate per pregnancy week increased markedly from three months before LMP up to about 25-week pregnancy and then remained relatively stable.

Maternal characteristics, maternal diagnoses, infant characteristics, and morbidity were compared with nonexposed infants. 


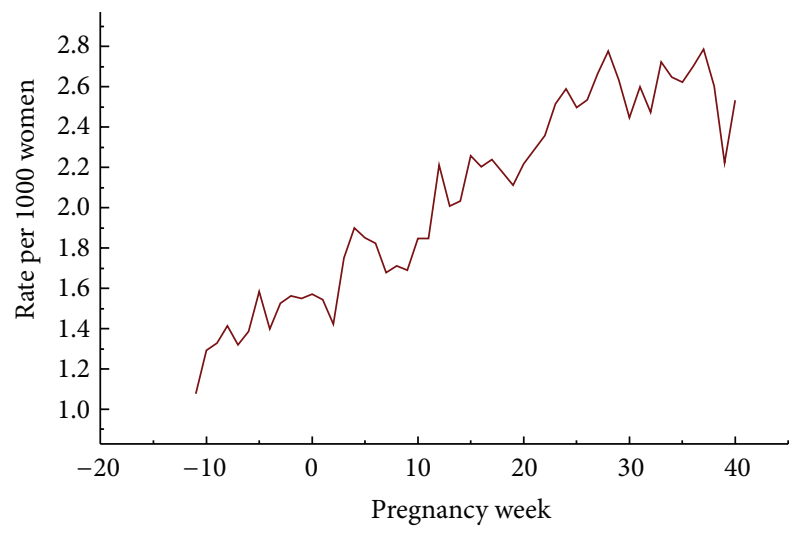

FIgURE 1: Prescriptions for antiasthmatic drugs (except for oral terbutaline) filled different pregnancy weeks, expressed as number per 1000 women, pregnant that week.

3.1. Maternal Characteristics. As seen in Table 2, women with asthma deviate in many aspects from other women; they are older, have lower parity, smoke more, and are more often overweight or obese.

After adjustment for year of delivery, maternal age, parity, smoking, and BMI, there was a weak increased risk for previous miscarriage. For one or two previous miscarriages the OR was 1.11 (95\% CI 1.05-1.17) and 1.12 (95\% CI 1.02-1.24), respectively. For three or more previous miscarriages it was 1.28 (95\% CI 1.13-1.46).

There was also an association with a period of unwanted childlessness as a sign of subfertility. For one year of unwanted childlessness the $\mathrm{OR}$ was marginally increased $(\mathrm{OR}=1.12$, 95\% CI 1.00-1.25) and for two or more years it was 1.16 (95\% CI 1.04-1.31).

Women who were born outside Sweden used antiasthmatic drugs less often than Swedish-born women. The OR for being born in another Nordic country was 0.89 (95\% CI 0.77$1.03)$ and for being born in a non-Nordic country 0.48 (95\% CI 0.45-0.51).

3.2. Maternal Diagnoses. When at least 100 outcomes were registered, risks were estimated for different groups of antiasthmatics used, irrespective of the use of other antiasthmatics.

Two chronic diseases, diabetes and hypertension, were studied (Table 3). Preexisting diabetes did not occur in statistical excess but preexisting hypertension did. Among other delivery diagnoses studied, all but two (gestational diabetes and premature rupture of membranes) occurred more often than expected. If the analysis of gestational diabetes was made without consideration to BMI, the OR was 1.31 (95\% CI 1.131.53).

The OR for gestational diabetes varied between different drug groups but for none was a significantly increased risk noted. Use of long-acting beta-2 agonists combined with steroids gave the highest OR which, however, was not significant $(\mathrm{OR}=1.30,95 \%$ CI $0.99-1.73)$.
TABLE 2: Some maternal characteristics of women who filled prescriptions for antiasthmatic drugs during the 2nd-3rd trimester of pregnancy compared with other women. Each variable is adjusted for all other variables and year of delivery. Odds ratio (OR) with 95\% confidence interval (95\% CI). Bold text marks statistical significance.

\begin{tabular}{|c|c|c|c|c|}
\hline Variable & $\begin{array}{l}\text { Number with } \\
\text { antiasthmatics }\end{array}$ & $\begin{array}{c}\text { Total } \\
\text { number }\end{array}$ & OR & $95 \% \mathrm{CI}$ \\
\hline \multicolumn{5}{|l|}{ Maternal age } \\
\hline$<20$ & 141 & 5393 & 0.83 & $0.70-1.00$ \\
\hline $20-24$ & 1081 & 43967 & 0.80 & $0.75-0.86$ \\
\hline $25-29$ & 2744 & 94135 & 1.00 & Reference \\
\hline $30-34$ & 3635 & 110921 & 1.17 & $1.11-1.23$ \\
\hline $35-39$ & 2350 & 60617 & 1.40 & $1.32-1.49$ \\
\hline $40-44$ & 570 & 12252 & 1.66 & $1.50-1.83$ \\
\hline$\geq 45$ & 32 & 647 & 1.80 & $1.25-2.60$ \\
\hline \multicolumn{5}{|l|}{ Parity } \\
\hline 1 & 4556 & 147467 & 1.00 & Reference \\
\hline 2 & 3866 & 120556 & 0.94 & $0.90-0.98$ \\
\hline 3 & 1458 & 42177 & 0.90 & $0.83-0.96$ \\
\hline$\geq 4$ & 673 & 17732 & 0.83 & $0.75-0.91$ \\
\hline \multicolumn{5}{|l|}{ Smoking } \\
\hline Unknown & 316 & 9788 & - & - \\
\hline No & 9298 & 297354 & 1.00 & Reference \\
\hline$<10$ cigs/day & 636 & 16119 & 1.32 & $1.21-1.43$ \\
\hline$\geq 10$ cigs/day & 303 & 4671 & 2.10 & $1.87-2.37$ \\
\hline \multicolumn{5}{|l|}{ BMI } \\
\hline Unknown & 675 & 21302 & - & - \\
\hline$<18.5$ & 165 & 7489 & 0.93 & $0.75-1.14$ \\
\hline $18.5-24.9$ & 4832 & 183964 & 1.00 & Reference \\
\hline $25-29.9$ & 2867 & 77158 & 1.11 & $1.05-1.17$ \\
\hline $30-34.9$ & 1286 & 26758 & 1.17 & $1.08-1.26$ \\
\hline$\geq 35$ & 728 & 11261 & 1.44 & $1.29-1.61$ \\
\hline Total number & 10553 & 327932 & & \\
\hline
\end{tabular}

The ORs for preeclampsia varied between 1.28 (95\% CI 1.12-1.38) for inhaled long-acting $\beta$-2 agonists and 1.85 (95\% CI 1.18-1.91) for montelukast but no significant difference between the estimates was found.

There was no increased risk for any PROM. If no adjustment was made for BMI, this did not affect the OR. When the analysis was restricted to PROM occurring at preterm births (PPROM) the OR was 0.86 (95\% CI 0.71-1.04).

The risk for a bleeding around delivery was increasedthe OR for antepartum bleeding was 1.14, for intrapartum bleeding 1.19 and for postpartum bleeding 1.07. These ORs obviously do not differ but the only one reaching statistical significance was that for intrapartum bleeding. For various groups of antiasthmatics the ORs varied little; the highest OR was for inhaled long-acting $\beta$-2 agonists (1.23, 95\% CI 1.081.41).

The increased risk for primary weak contractions was highest and statistically significant after short-acting $\beta-2$ 
TABLE 3: Diagnoses among women who filled prescriptions for antiasthmatic drugs during the 2nd-3rd trimester of pregnancy. Odds ratios (OR) or risk ratios (RR) with $95 \%$ confidence intervals (95\% CI) adjusted for year of delivery, maternal age, parity, smoking, and BMI. Bold text marks statistical significance.

\begin{tabular}{|c|c|c|c|c|}
\hline Diagnosis & $\begin{array}{l}\text { With } \\
\text { drug }\end{array}$ & $\begin{array}{c}\text { In } \\
\text { population }\end{array}$ & OR/RR & $95 \% \mathrm{CI}$ \\
\hline Preexisting diabetes & 69 & 1687 & 1.15 & $0.90-1.47$ \\
\hline $\begin{array}{l}\text { Preexisting } \\
\text { hypertension }\end{array}$ & 87 & 1543 & 1.29 & $1.03-1.61$ \\
\hline $\begin{array}{l}\text { Gestational } \\
\text { diabetes }\end{array}$ & 175 & 3929 & 1.05 & $0.89-1.23$ \\
\hline Preeclampsia & 644 & 13701 & 1.33 & $1.27-1.44$ \\
\hline $\begin{array}{l}\text { Hyperemesis } \\
\text { gravidarum }\end{array}$ & 36 & 710 & 1.50 & $1.06-2.10$ \\
\hline Placenta previa & 68 & 1312 & 1.48 & $1.16-1.90$ \\
\hline Placenta abruption & 64 & 1337 & 1.37 & $1.03-1.72$ \\
\hline $\begin{array}{l}\text { Premature rupture } \\
\text { of membranes }\end{array}$ & 205 & 6162 & 0.97 & $0.84-1.12$ \\
\hline $\begin{array}{l}\text { Bleeding around } \\
\text { delivery }\end{array}$ & 912 & 24855 & 1.11 & $1.03-1.14$ \\
\hline $\begin{array}{l}\text { Primary weak } \\
\text { contractions }\end{array}$ & 375 & 9738 & 1.12 & $1.01-1.25$ \\
\hline $\begin{array}{l}\text { Induction of } \\
\text { delivery }\end{array}$ & 1830 & 44006 & 1.24 & $1.18-1.31$ \\
\hline Caesarean section & 2319 & 56198 & 1.23 & $1.17-1.29$ \\
\hline $\begin{array}{l}\text { Instrumental } \\
\text { vaginal delivery* }\end{array}$ & 849 & 24799 & 1.16 & $1.08-1.25$ \\
\hline
\end{tabular}

agonists (OR $=1.15,95 \%$ CI 1.01-1.31) while for the other drug groups it was lower and not statistically significant.

The increased risk for delivery induction varied slightly between different antiasthmatic drug groups between 1.22 (95\% CI 1.14-1.30) for short-acting $\beta$-2 agonists to 1.41 (95\% CI 1.26-1.57) for long-acting $\beta-2$ agonists.

The Caesarean section rate was increased after maternal use of antiasthmatics. The highest OR value was seen after use of montelukast $(\mathrm{OR}=1.88,95 \% \mathrm{CI} 1.42-2.51)$ and the lowest OR after short-acting $\beta-2$ agonists (OR $=1.19,95 \% \mathrm{CI}$ 1.13-1.26). These differences may not be random. Also the OR for instrumental vaginal delivery was high after the use of montelukast $(\mathrm{OR}=1.84,95 \% \mathrm{CI} 1.20-2.81)$ and low after the use of short-acting $\beta-2$ agonists (OR $=1.13$, 95\% CI 1.03-1.24).

3.3. Preterm Birth, Low Birth Weight, and SGA. These outcomes were analyzed in singleton pregnancies, exposed to antiasthmatic drugs during the second or third trimester up to week 37. Later exposure could not affect preterm birth. When oral terbutaline was included in the analysis, a significantly increased risk for preterm birth was seen $(\mathrm{OR}=$ 1.48 , 95\% CI 1.38-1.59) but when such treatments were excluded, the risk for preterm birth decreased and was no longer significant (Table 4). The risks for low birth weight and for SGA were, however, significantly increased. Adjustment for being born in Sweden or abroad did not change the OR for preterm birth and increased slightly but not significantly that for low birth weight and for SGA.

For specific antiasthmatic drugs, however, an increased risk for preterm birth was seen; inhaled fixed combinations of long-acting $\beta-2$ agonists with other antiasthmatics (mainly corticosteroids) and xanthines or montelukast. For low birth weight, the risk was strong but not significant with xanthines or montelukast. For SGA a significant increase was seen after any antiasthmatic. This effect seemed to be stronger after long-acting $\beta$-2-agonists, fixed combinations of such drugs with other antiasthmatics (mainly corticosteroid), and xanthines or montelukast. The effect of inhaled steroids was lower.

3.4. Neonatal Diagnoses. These outcomes were studied in all infants. Table 5 shows risk estimates for seven specified neonatal diagnoses.

For three conditions, statistically significant risk increases were seen: hypoglycemia, respiratory diagnoses, and low Apgar score. The risk to have any of these seven diagnoses was slightly but statistically significant increased. When the latter risk was compared for different types of antiasthmatic drugs, only little variation was seen. The highest $\mathrm{OR}$ was seen for montelukast (OR $=1.21,95 \%$ CI $0.88-1.85)$ but it was not statistically significant. When infants exposed for the latter drug were analyzed for specific outcomes, the highest OR was for hypoglycemia (OR $=1.92,95 \%$ CI 0.99-3.35).

\section{Discussion}

The exposure studied in this paper is defined as use of antiasthmatic medicines. Such patients were identified from prescriptions filled after the first trimester of pregnancy. The study by Källén and Otterblad Olausson [9] on antiasthmatic use after the first trimester was based on information from antenatal care which meant that the patient had been prescribed such drugs but it was not known if they had actually filled the prescription and used the drug. In the present setting there is still an uncertainty whether the patient used the drugs during pregnancy and if so when she used them. Not using the prescribed drug can have two effects. It may prevent a direct harmful drug effect on the pregnancy outcome or it can mean that the asthma of the patient may be undertreated.

No direct information is available on the underlying disease. In most cases, asthma was probably present but some patients may have got the drugs for other reasons including chronic obstructive pulmonary disease. This is, for instance, probably the case for the few women who got indacaterol or thiotropium. This also means that we have no direct means of adjusting for severity of asthma.

One group of women may not have a pulmonary disease at all but had got oral adrenergics as uterolytics. In Sweden, the main drug used for this purpose is terbutaline (and atosiban) and cases with terbutaline were excluded from the analyses. A few of the 39 women who used other oral adrenergics may have got it as uterolytics but the indication 
TABLE 4: Preterm birth, low birth weight, and small-for-gestational age (SGA) in women who got prescriptions for antiasthmatic drugs prior to pregnancy week 37 . Odds ratios (OR) with $95 \%$ confidence intervals (95\% CI) adjusted for year of delivery, maternal age, parity, smoking, and BMI. Bold text marks statistical significance.

\begin{tabular}{lccccc}
\hline Outcome & Antiasthmatic drug used & Number with outcome & Total number & OR & $95 \%$ CI \\
\hline \multirow{4}{*}{ Preterm birth } & Any & 542 & 9742 & 1.08 & $0.98-1.18$ \\
& Inhaled short-acting $\beta$-2 agonist & 385 & 6741 & 1.10 & $0.99-1.22$ \\
& Inhaled long-acting $\beta$-2 agonist & 98 & 1571 & $\mathbf{1 . 2 3}$ & $\mathbf{1 . 0 0 - 1 . 5 1}$ \\
& Inhaled corticosteroid & 329 & 5909 & 1.08 & $0.96-1.21$ \\
\multirow{2}{*}{ Low birth weight } & Montelukast & 20 & 216 & $\mathbf{1 . 8 2}$ & $\mathbf{1 . 1 5 - 2 . 8 7}$ \\
\hline \multirow{2}{*}{ SGA } & Any & 368 & 9728 & $\mathbf{1 . 1 2}$ & $\mathbf{1 . 0 0 - 1 . 2 4}$ \\
& Montelukast & 13 & 215 & 1.72 & $0.94-2.88^{\#}$ \\
\hline & Any & 292 & 9727 & $\mathbf{1 . 3 7}$ & $\mathbf{1 . 2 1 - 1 . 5 4}$ \\
& Inhaled short-acting $\beta$-2 agonist & 194 & 6731 & $\mathbf{1 . 3 1}$ & $\mathbf{1 . 1 3 - 1 . 5 1}$ \\
& Inhaled long-acting $\beta$-2 agonist & 68 & 1536 & $\mathbf{1 . 9 2}$ & $\mathbf{1 . 5 9 - 2 . 4 5}$ \\
\hline
\end{tabular}

Among 323054 infants in the population with known gestational duration, 15850 were preterm, among 322770 with known birth weight, 10481 were low birth weight, among 322599 infants with known gestational duration, known birth weight, and sex, and 7183 were SGA.

${ }^{\#} \mathrm{RR}$ as observed/expected number with exact $95 \% \mathrm{CI}$.

TABLE 5: Neonatal diagnosis in infants whose mothers got prescriptions on antiasthmatic drugs during trimester 2 or 3. Odds ratios (OR) or risk ratio (RR) with $95 \%$ confidence intervals $(95 \% \mathrm{CI})$ adjusted for year of delivery, maternal age, parity, smoking, and BMI. Bold text marks statistical significance.

\begin{tabular}{|c|c|c|c|c|}
\hline Outcome & $\begin{array}{l}\text { With } \\
\text { drug }\end{array}$ & $\begin{array}{c}\text { In } \\
\text { population }\end{array}$ & $\mathrm{OR} / \mathrm{RR}$ & $95 \% \mathrm{CI}$ \\
\hline Hypoglycemia & 309 & 6884 & 1.25 & $1.11-1.40$ \\
\hline Fetal distress & 6 & 160 & 1.06 & $0.39-2.31^{\#}$ \\
\hline $\begin{array}{l}\text { Respiratory } \\
\text { diagnosis }\end{array}$ & 567 & 14055 & 1.19 & $1.09-1.29$ \\
\hline $\begin{array}{l}\text { Apgar score }<7 \text { at } 5 \\
\text { minutes* }\end{array}$ & 170 & 4013 & 1.21 & $1.03-1.41$ \\
\hline $\begin{array}{l}\text { Intracranial } \\
\text { hemorrhage }\end{array}$ & 16 & 483 & 0.90 & $0.54-1.41$ \\
\hline CNS diagnosis & 127 & 3525 & 1.04 & $0.87-1.25$ \\
\hline Jaundice & 417 & 12042 & 1.01 & $0.92-1.12$ \\
\hline $\begin{array}{l}\text { Any of these } \\
\text { diagnoses }\end{array}$ & 1212 & 32591 & 1.09 & $1.06-1.10$ \\
\hline
\end{tabular}

for the use of oral salbutamol in Sweden is not threatening premature delivery; this is actually a contraindication.

Some use of oral terbutaline as an asthma medicine also occurs, but scrutiny of the prescription instructions shows that the vast majority refer to the treatment of premature contractions and most such prescriptions were from the last part of the pregnancy. If no other antiasthmatic drug was documented, such exposures were therefore disregardedquite obviously they will be associated with preterm births and other complications.
The rate of pregnant women who got prescriptions for antiasthmatic drugs increased during pregnancy (Figure 1). This could be an effect of increasing asthmatic problems during pregnancy or an intensification of treatment of asthma. Most studies have not found a general worsening of asthma during pregnancy which speaks against the first alternative.

When an association was present between maternal use of antiasthmatic drugs and a negative pregnancy outcome, various explanations may exist. Women using these drugs differ from other women in many aspects which may confound the analysis. Adjustment was made for maternal age, parity, smoking, and BMI and in some situations also for the case if the mother was born in Sweden or outside Sweden. On the other hand no adjustment was made for previous miscarriages or subfertility - these are reasonably expressions of the asthma or its treatment before the relevant pregnancy.

Women with asthma also have much comorbidity to judge from the use of other drugs [5]. Both asthma and comorbidity can confound the analysis. Sometimes this problem has been attacked by comparing outcome after the use of antiasthmatic drugs with that after untreated asthma. It is, however, likely that the latter patients have less severe asthma than those getting treatment. The nature of the antiasthmatics used can give some hints. Short-acting beta- 2 agonists are used in order to treat acute attacks but are also used at less severe or temporary asthma as the only drug. Controller drugs (long-acting beta- 2 agonists or inhaled corticosteroids) may in moderate to severe cases prevent acute attacks. Use of xanthines or montelukast may indicate more severe asthma. In the present material there are some data which suggest that the use of the latter two drug categories is associated with a higher risk for complications which could indicate an effect of more severe asthma. 
Maternal obstetric morbidity was increased in women using antiasthmatics. The risks were increased for preeclampsia, placenta previa, placental abruption, primary weak contractions, hemorrhage around delivery, and caesarean section which agrees well with the results summarized in reviews $[1,2,10]$.

For three diagnoses, no significantly increased risk existed, preexisting diabetes, gestational diabetes, and PROM. There has been some discussion in the literature whether diabetes type 1 and asthma have a tendency to coexist but a twin study [11] found no evidence for this in adults $(\mathrm{OR}=1.03$, 95\% CI 0.52-2.00).

Studies on gestational diabetes $[9,10,12]$ gave ORs varying between 1.11 and 2.28. In the previous Swedish study we found an OR of 1.29 (95\% CI 1.14-1.95) for antiasthmatic users after the first trimester. In the present study we found much lower ORs and none reached statistical significance. It should be stressed that in the earlier paper no adjustment for BMI was made, which is a strong risk factor for gestational diabetes and which is also associated with an asthma risk (Table 2). This seemed to explain the difference in results, because when the adjustment for BMI was left out in the present analysis, a significant risk appeared of the same magnitude as that obtained in the earlier study.

Some previous studies found an increased risk for PROM $[9,12,13]$ and other studies did not $[10,14,15]$. In one study [14] the OR for any PROM was 0.99 but it was 1.18 for PPROM. In the present study no significant risk was seen, neither for any PROM, nor for PPROM.

Primary weak contractions occurred at an increased rate after maternal antiasthmatic drug use. The highest and only significant risk estimate was for short-acting $\beta-2$ agonists which could be a direct effect of the drug on the uterus.

In contrast to most previous large studies there was no significant increased risk for preterm births in women who got antiasthmatic drug prescriptions before week 37 . Such an effect was seen, however, when combinations of long-acting beta- 2 agonists and inhaled corticosteroids and more marked when xanthines or montelukast had been used. Use of these drugs may mark more severe asthma.

A significant effect was seem on intrauterine growth retardation $[9,13-15]$. It may be an expression of asthma severity and may be due to a relative asphyxia during pregnancy. This agrees with the conclusions drawn by Firoozi et al. [16] where the risk for SGA depended on asthma severity. A possible explanation was suggested in a study on placental vascular function at maternal asthma [17].

Among neonatal symptoms which were increased at maternal asthma are hypoglycemia, respiratory diagnoses, and low Apgar score. No increase in the risk for jaundice was seen in contrast to an earlier finding [18]. The association with infant hypoglycemia has been described previously [9]. Our data indicate that it is not secondary to maternal preexisting or gestational diabetes as no increased risk for these conditions was seen. The increased risk for respiratory problems and a low Apgar score agrees with previous data [18].

Both the rates of caesarean sections and instrumental vaginal deliveries were increased among the studied women.
An increased risk of caesarean section at maternal asthma has been demonstrated repeatedly. The explanation may at least partly be found in the obstetric complications described above.

To conclude, both with regard to maternal obstetric complications and neonatal complications, an increased risk for negative outcomes was found. This was difficult to link to specific antiasthmatic drug use but the general pattern indicates a confounding by indication and that poorly controlled asthma may carry the largest risk [19]. Probably intense asthma therapy can be recommended without fear for harmful drug effects. Enough data are not available for the newest drugs, montelukast, and notably omalizumab.

\section{Ethical Approval}

The study was performed within the responsibilities of the National Board of Health and Welfare and therefore no ethical approval from outside ethical committees was needed.

\section{Conflict of Interests}

None of the authors declares any conflict of interests.

\section{References}

[1] B. Källén, "The safety of asthma medications during pregnancy," Expert Opinion on Drug Safety, vol. 6, no. 1, pp. 15-26, 2007.

[2] G. Wang, V. E. Murphy, J. Namazy et al., "The risk of maternal and placental complications in pregnant women with asthma: a systematic review and meta-analysis," Journal of Maternal-Fetal and Neonatal Medicine, vol. 27, no. 9, pp. 934-942, 2014.

[3] V. E. Murphy, G. Wang, J. A. Namazy et al., “The risk of congenital malformations, perinatal mortality and neonatal hospitalisation among pregnant women with asthma: a systematic review and meta-analysis," BJOG : An International Journal of Obstetrics and Gynaecology, vol. 120, no. 7, pp. 812-822, 2013.

[4] S. Eltonsy, F.-Z. Kettani, and L. Blais, "Beta 2 -agonists use during pregnancy and perinatal outcomes: a systematic review," Respiratory Medicine, vol. 108, no. 1, pp. 9-33, 2014.

[5] B. Källén, "Maternal asthma and use of antiasthmatic drugs in early pregnancy and congenital malformations in the offspring," Journal of Pulmonary \& Respiratory Medicine, vol. 4, p. 166, 2014.

[6] National Board of Health and Welfare. Centre for Epidemiology, "The Swedish Medical Birth Register-a summary of content and quality," 2003, http://www.socialstyrelsen .se/Publikationer2003/2003-112-3.

[7] B. Wettermark, C. M. Fored, A. Leimanis et al., "The new Swedish prescribed drug register-opportunities for pharmacoepidemiological research and experience from the first six months," Pharmacoepidemiology and Drug Safety, vol. 16, no. 7, pp. 726735, 2007.

[8] B. Kallen, "A birth weight for gestational age standard based on data in the Swedish Medical Birth Registry, 1985-1989," European Journal of Epidemiology, vol. 11, no. 5, pp. 601-606, 1995.

[9] B. Källén and P. Otterblad Olausson, "Use of anti-asthmatic drugs during pregnancy. 1. Maternal characteristics, pregnancy and delivery complications," European Journal of Clinical Pharmacology, vol. 63, no. 4, pp. 363-373, 2007. 
[10] P. Mendola, S. K. Laughon, T. I. Männistö et al., "Obstetric complications among US women with asthma," American Journal of Obstetrics \& Gynecology, vol. 208, no. 2, pp. 127-e8, 2013.

[11] S. Thomsen, D. L. Duffy, K. O. Kyvik, A. Skytthe, and V. Backer, "Relationship between type 1 diabetes and atopic diseases in a twin population," Allergy, vol. 66, no. 5, pp. 645-647, 2011.

[12] S. W. Wen, K. Demissie, and S. Liu, "Adverse outcomes in pregnancies of asthmatic women: results from a Canadian population," Annals of Epidemiology, vol. 11, no. 1, pp. 7-12, 2001.

[13] E. Sheiner, M. Mazor, A. Levy, A. Wiznitzer, and A. Bashiri, "Pregnancy outcome of asthmatic patients: a population-based study," Journal of Maternal-Fetal and Neonatal Medicine, vol. 18, no. 4, pp. 237-240, 2005.

[14] K. Demissie, M. B. Breckenridge, and G. G. Rhoads, "Infant and maternal outcomes in the pregnancies of asthmatic women," American Journal of Respiratory and Critical Care Medicine, vol. 158, no. 4, pp. 1091-1095, 1998.

[15] S. Liu, S. W. Wen, K. Demissie, S. Marcoux, and M. S. Kramer, "Maternal asthma and pregnancy outcomes: a retrospective cohort study," The American Journal of Obstetrics and Gynecology, vol. 184, no. 2, pp. 90-96, 2001.

[16] F. Firoozi, C. Lemière, F. M. Ducharme et al., "Effect of maternal moderate to severe asthma on perinatal outcomes," Respiratory Medicine, vol. 104, no. 9, pp. 1278-1287, 2010.

[17] V. L. Clifton, W. B. Giles, R. Smith et al., "Alterations of placental vascular function in asthmatic pregnancies," American Journal of Respiratory and Critical Care Medicine, vol. 164, no. 4, pp. 546-553, 2001.

[18] B. Källén and P. O. Olausson, "Use of anti-asthmatic drugs during pregnancy. 2. Infant characteristics excluding congenital malformations," European Journal of Clinical Pharmacology, vol. 63, no. 4, pp. 375-381, 2007.

[19] L. Tamási, I. Horváth, A. Bohács, V. Müller, G. Losonczy, and M. Schatz, "Asthma in pregnancy-immunological changes and clinical management," Respiratory Medicine, vol. 105, no. 2, pp. 159-164, 2011. 


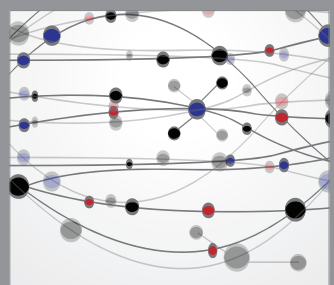

The Scientific World Journal
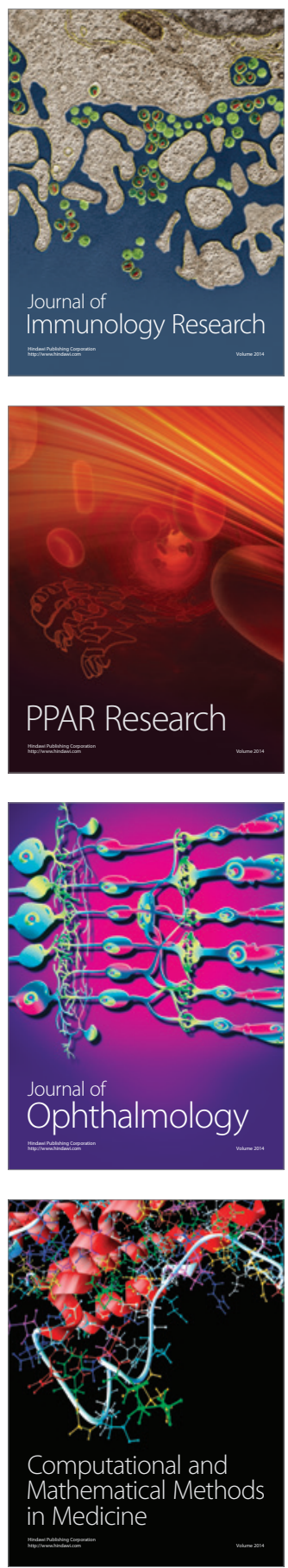

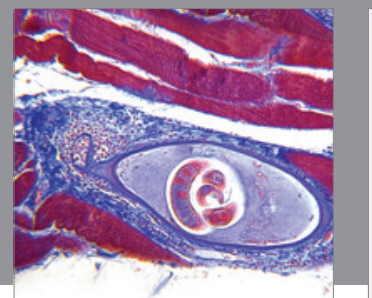

Gastroenterology

Research and Practice
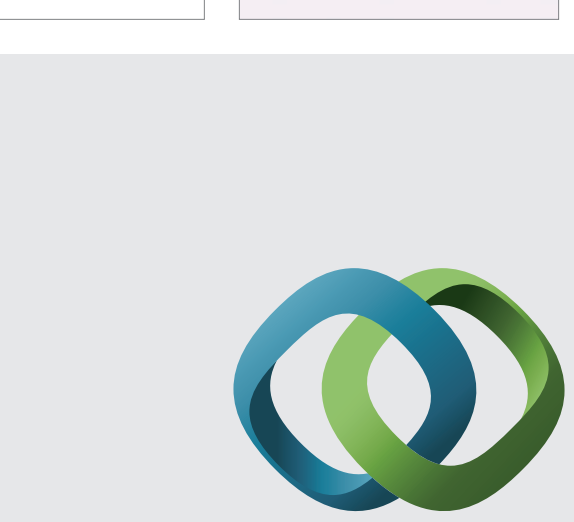

\section{Hindawi}

Submit your manuscripts at

http://www.hindawi.com
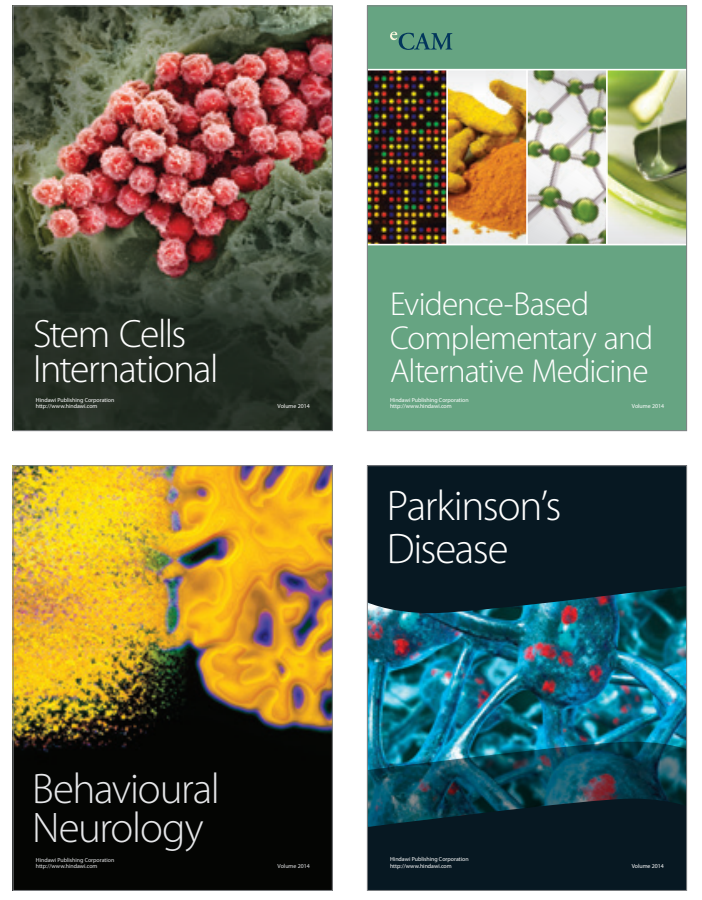
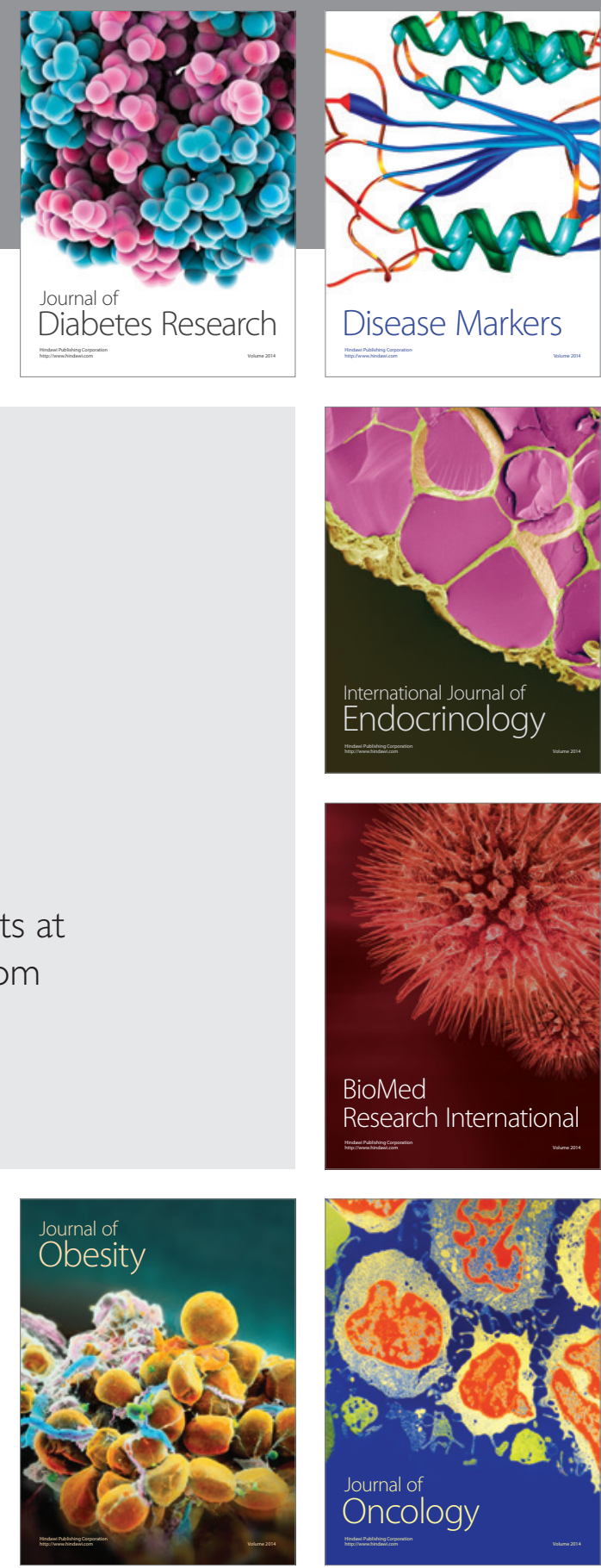

Disease Markers
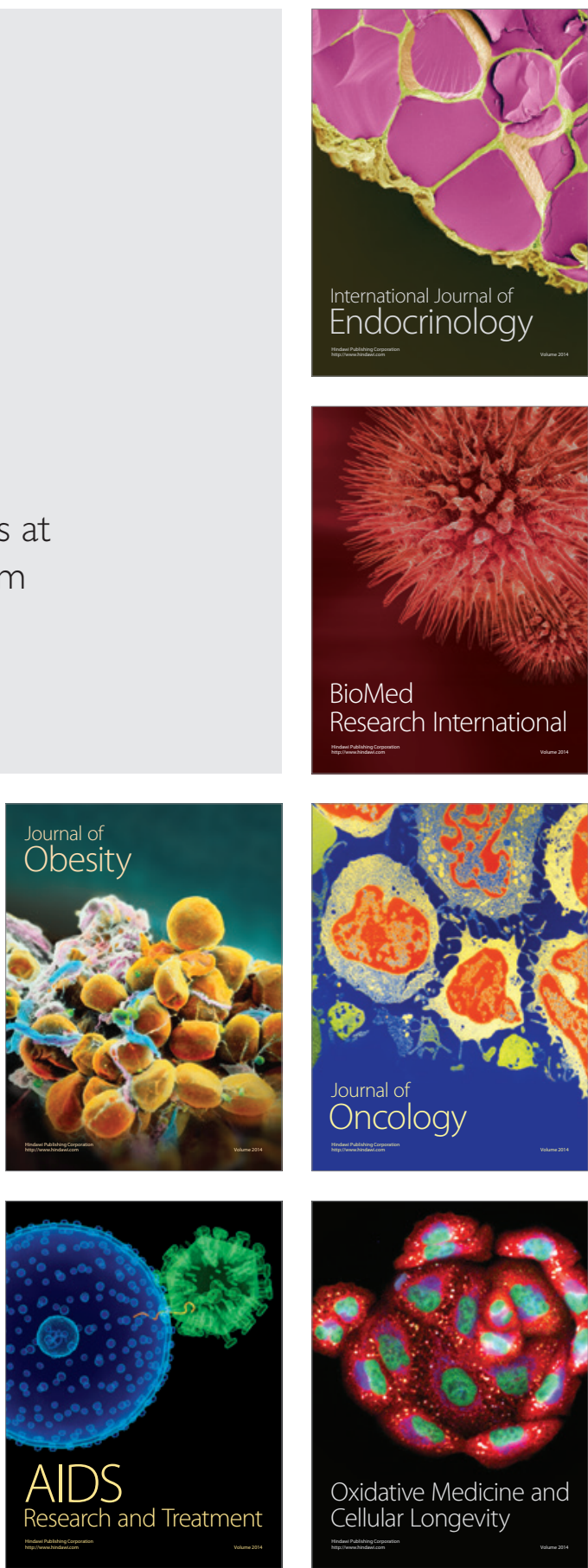